\title{
DESENVOLVIMENTO REGIONAL E ESPORTE AMADOR: AS DIMENSÕES TERRITORIAIS DOS JOGOS ABERTOS DE SANTA CATARINA
}

\section{REGIONAL DEVELOPMENT AND AMATEUR SPORT: THE TERRITORIAL DIMENSIONS OF OPEN GAMES SANTA CATARINA}

\author{
Marcos Antônio Mattedi \\ Universidade Regional de Blumenau - Blumenau - SC - Brasil \\ Camila da Cunha Nunes \\ Universidade Regional de Blumenau - Blumenau - SC - Brasil
}

\begin{abstract}
Resumo: O presente texto aborda as questões relativas à relação entre esporte e território no Estado de Santa Catarina. O estado de Santa Catarina se caracteriza pela especialização e dispersão das atividades produtivas no território. No entanto, a dinâmica de espacialização observada no esporte amador possui uma lógica de territorialização própria e distinta do esporte profissional, e não acompanha a lógica de diferenciação espacial produtiva. A partir disso, este estudo procura examinar as características específicas por meio do qual o esporte amador se territorializa no Estado de Santa Catarina. Para tanto, realizou-se o processo de territorialização baseado na análise da competição esportiva amadora de maior impacto no território catarinense, os Jogos Abertos de Santa Catarina.
\end{abstract}

Palavras-chave: Desenvolvimento Regional. Território. Esporte amador. Jogos Abertos de Santa Catarina.

Abstract: This paper addresses the issues relating to the relationship between sport and territory in the state of Santa Catarina. The state of Santa Catarina is characterized by specialization and dispersion of productive activities in the territory. However, the dynamics of spacialization observed in the amateur sport has a logic of its own and distinct of territorialization from the professional sport, and does not accompany the productive spatial differentiation logic. From this, this study seeks to examine the specific features by which the amateur sport to expand in the territory of the state of Santa Catarina. To this end, was used the process of territorialization based on 
analysis of amateur sports competition with the greatest impact on the state of Santa Catarina, the Open Games of Santa Catarina.

Keywords: Regional Development. Territory. Amateur sport. Open Games of Santa Catarina.

\section{INTRODUÇÃO}

O esporte vem se convertendo num elemento central no desenvolvimento das sociedades modernas (UNOSDP, 2012). Ao mesmo tempo, a realização de eventos esportivos passaram a ser considerados como vetores de grandes transformações territoriais, pela localização dos equipamentos, mas também pelo fluxo de pessoas. Por isso, o esporte vem assumindo uma atenção crescente junto à opinião pública e o meio científico brasileiros. Por um lado, esse processo está associado à realização de grandes eventos esportivos como a Copa do Mundo de Futebol e a Olimpíada; por outro, a relação entre esporte e território se torna cada vez mais complexa e vem assumindo um estatuto de investigação científica mais central. Portanto, as questões referentes à relação entre esporte e território se tornam centrais para o entendimento dos processos em Desenvolvimento Regional. Nesse sentido, o Estado de Santa Catarina (figura 1) ilustra bem os dilemas e perspectivas relacionadas à centralidade da questão da relação entre esporte e o território. 
Figura 1. Mapa de Santa Catarina

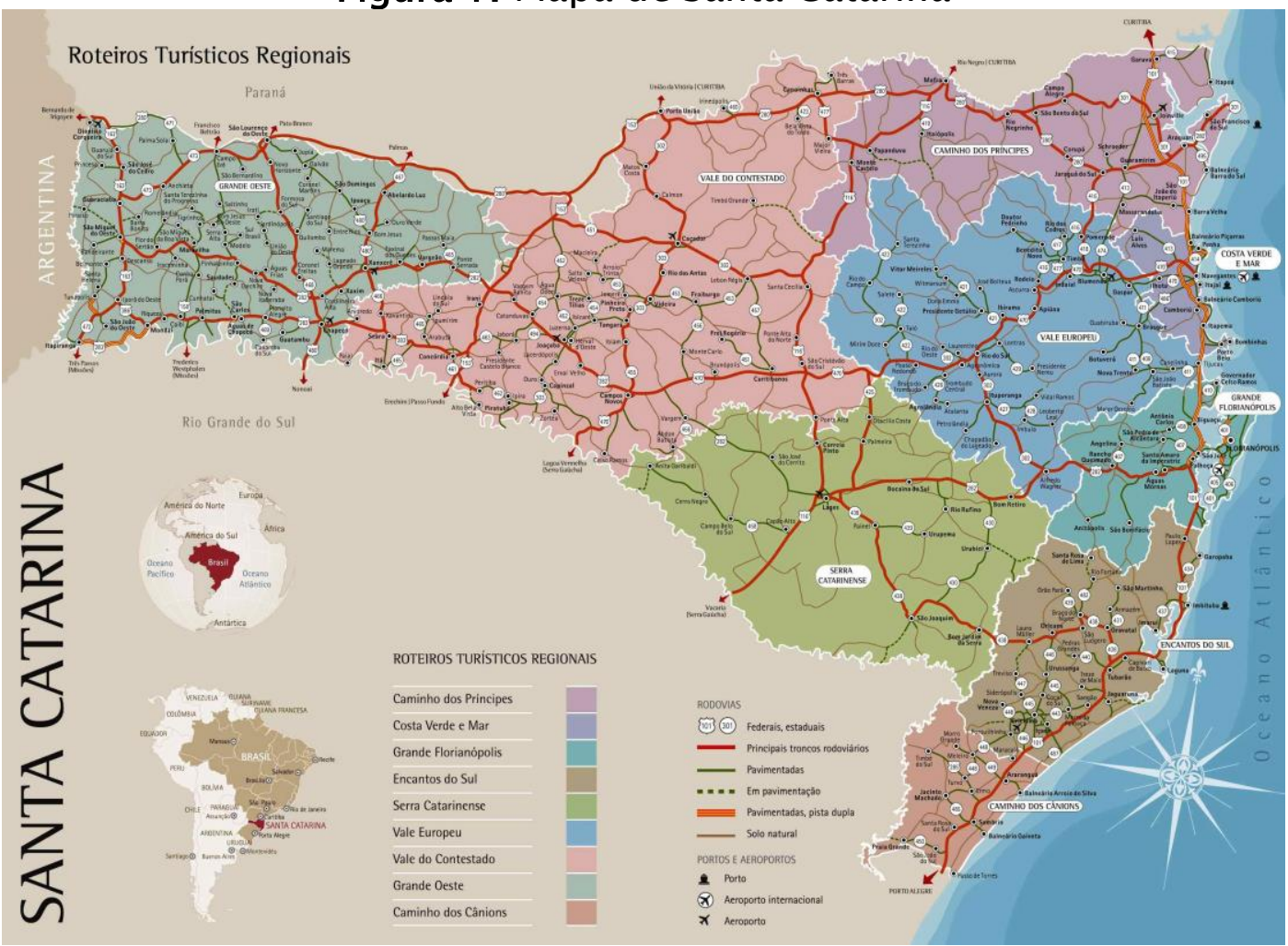

Fonte: Editora Letras Brasileiras, 2014.

Diante de um contexto nacional marcado por um crescente processo de concentração espacial da população e da produção, o Estado de Santa Catarina sempre foi descrito como uma experiência atípica. Os elementos centrais desta análise dizem respeito, principalmente, aos fatores econômicos e urbanos do padrão de desenvolvimento predominante. Por um lado, o processo de industrialização do Estado de Santa Catarina baseou-se em pequenas e medias indústrias (HERING, 1987; CEAG, 1980; RAUD, 1999). E, por outro, o processo de urbanização observada a partir do final da década de 1950 se estabelece em cidades medias (VIDOR, 1986; SIEBERT, 2001). Esse processo impediu o surgimento de polos de concentração espacial da produção e da população como nos demais estados. Esse padrão de desenvolvimento regional vai se manifestar de forma ambivalente no desenvolvimento de diversas atividades socioeconômicas.

Um reflexo desse processo diz respeito à formação socioespacial e desenvolvimento da estrutura produtiva (GOULARTI FILHO, 2007). O Estado de Santa Catarina se caracteriza pela especialização e dispersão 
das atividades produtivas no território. Isso acarreta um desenvolvimento econômico industrial descentralizado espacialmente. Na região Sul há concentração dos polos cerâmicos, carvão, vestuário e descartáveis plásticos; no Oeste, alimentar e móveis; na região do Vale do Itajaí, dos polos têxtil, vestuário, naval e cristal; no Norte do estado, da metalurgia, máquinas e equipamentos, material elétrico, autopeças, plástico, confecções e mobiliário; e, na parte serrana, o madeireiro. Além disso, a indústria tecnológica se destaca nos municípios de Florianópolis, Blumenau, Chapecó, Criciúma e Joinville. Essa forma de propagação descentralizada da atividade ocasiona a disseminação da diversidade de polos.

Figura 2. Principais concentrações produtivas no estado de Santa Catarina

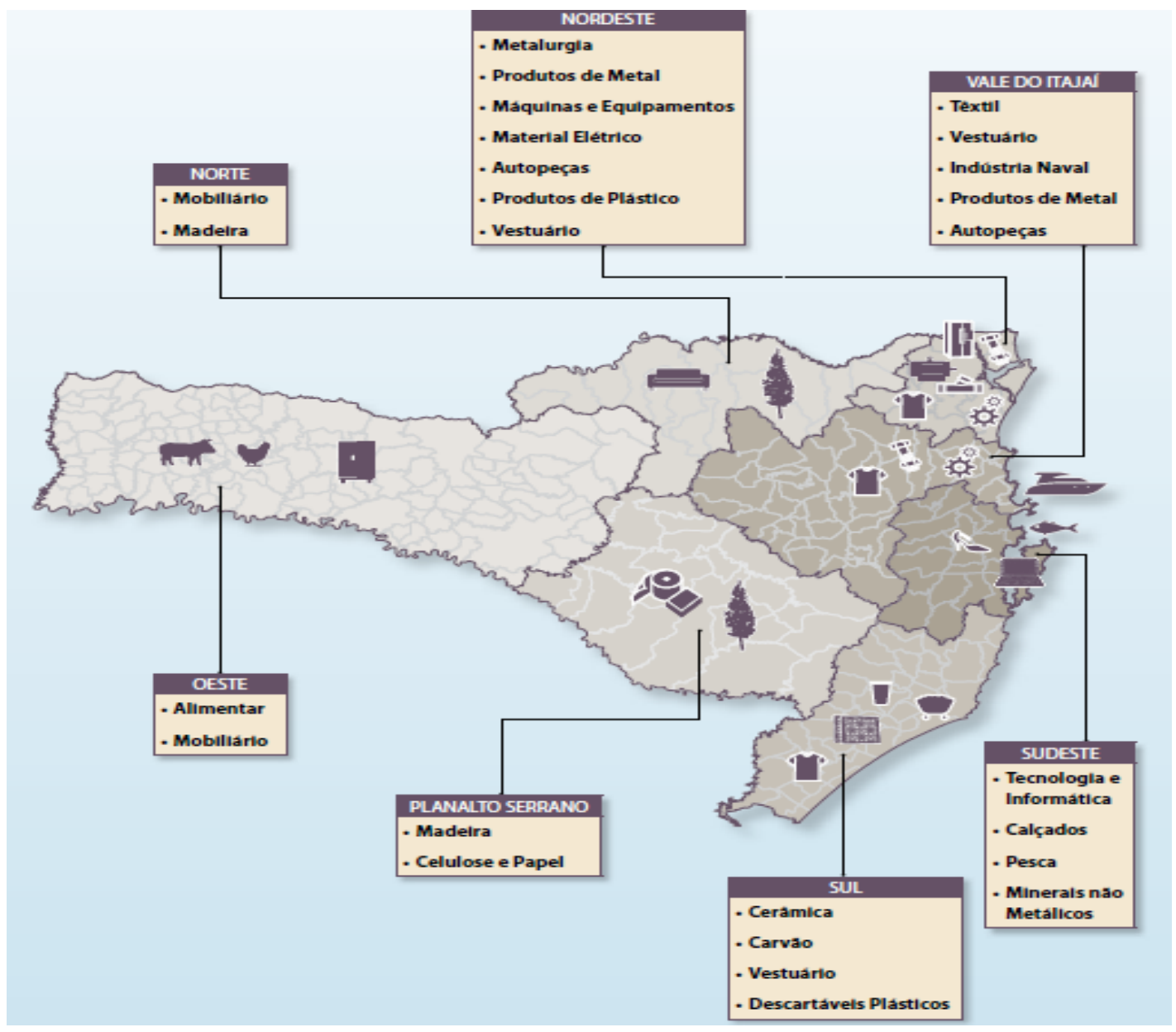

Fonte: FIESC, 2013, p. 12. 
O futebol profissional parece também obedecer esse mesmo processo de desconcentração ou dispersão espacial. Tajes Jr. (2012) observou esse fenômeno ao considerar a diversidade de campeões estaduais em comparação aos demais campeonatos estaduais de futebol, partindo da relação entre desenvolvimento econômico e a maior variação de campeões do Campeonato Estadual de Futebol. A pesquisa se delineou por meio de um estudo comparativo entre as potencialidades econômicas e institucionais das regiões catarinenses com o futebol profissional em Santa Catarina no período de 1960-2010. Os resultados revelaram que o futebol pode ser uma variável para o desenvolvimento local e regional. Isso porque, durante o período analisado, os títulos de campeão e vice-campeão do Campeonato Estadual de Futebol se concentram nas regiões mais dinâmicas economicamente.

No entanto, no que se refere ao esporte amador, parece haver um fenômeno diferente. A dinâmica de espacialização observada com relação ao Campeonato Catarinense de Futebol não obedece o mesmo padrão nos Jogos Abertos de Santa Catarina - JASC. Os JASC constituem uma competição promovida pela Fundação Catarinense de Desporto FESPORTE, que ocorre anualmente desde 1960, e os municípios buscam a conquista do título geral. Todavia, somente três municípios do estado figuram entre os ganhadores do título geral (quadro 1). E esses três municípios (Blumenau, Joinville e Florianópolis) se localizam na região litorânea (figura 3). Essa evidência contradiz a lógica apresentada pelas outras atividades, até então, de descentralização. Desse modo, temos como questão problema: porque o esporte amador não apresenta a mesma lógica de especialização territorial que o esporte profissional?

Quadro 1. Campeões dos JASC no período de 1960-2013

\begin{tabular}{|c|c|}
\hline Ano & Campeão Geral \\
\hline 1960 & Florianópolis \\
\hline 1961 & Florianópolis \\
\hline 1962 & Blumenau \\
\hline 1963 & Joinville \\
\hline 1964 & Blumenau \\
\hline 1965 & Blumenau \\
\hline 1966 & Joinville \\
\hline 1967 & Blumenau \\
\hline
\end{tabular}




\begin{tabular}{|c|c|}
\hline 1968 & Blumenau \\
\hline 1969 & Blumenau \\
\hline 1970 & Blumenau \\
\hline 1971 & Blumenau \\
\hline 1972 & Blumenau \\
\hline 1973 & Blumenau \\
\hline 1974 & Blumenau \\
\hline 1975 & Blumenau \\
\hline 1976 & Blumenau \\
\hline 1977 & Blumenau \\
\hline 1978 & Blumenau \\
\hline 1979 & Blumenau \\
\hline 1980 & Blumenau \\
\hline 1981 & Blumenau \\
\hline 1982 & Blumenau \\
\hline 1983 & * \\
\hline 1984 & Blumenau \\
\hline 1985 & Blumenau \\
\hline 1986 & Blumenau \\
\hline 1987 & Blumenau \\
\hline 1988 & Blumenau \\
\hline 1989 & Blumenau \\
\hline 1990 & Blumenau \\
\hline 1991 & Blumenau \\
\hline 1992 & Joinville \\
\hline 1993 & Joinville \\
\hline 1994 & Blumenau \\
\hline 1995 & Blumenau \\
\hline
\end{tabular}


Desenvolvimento Regional e Esporte Amador: as dimensões territoriais...

Continuação

\begin{tabular}{|c|c|}
\hline Ano & Campeão Geral \\
\hline 1996 & Blumenau \\
\hline 1997 & Blumenau \\
\hline 1998 & Blumenau \\
\hline 1999 & Blumenau \\
\hline 2000 & Blumenau \\
\hline 2001 & Florianópolis \\
\hline 2002 & Florianópolis \\
\hline 2003 & Blumenau \\
\hline 2004 & Blumenau \\
\hline 2005 & Blumenau \\
\hline 2006 & Blumenau \\
\hline 2007 & Blumenau \\
\hline 2008 & ** \\
\hline 2009 & Florianópolis \\
\hline 2010 & Florianópolis \\
\hline 2011 & Florianópolis \\
\hline 2012 & Florianópolis \\
\hline 2013 & Blumenau \\
\hline
\end{tabular}

* Devido à enchente ocorrida no Vale do Itajaí neste ano a competição não foi realizada.

** A competição teve seu início, mas foi cancelada no segundo dia, devido à enchente ocorrida na região no período dos jogos.

Fonte: FESPORTE (2014).

Figura 3. Mapa dos municípios campeões gerais

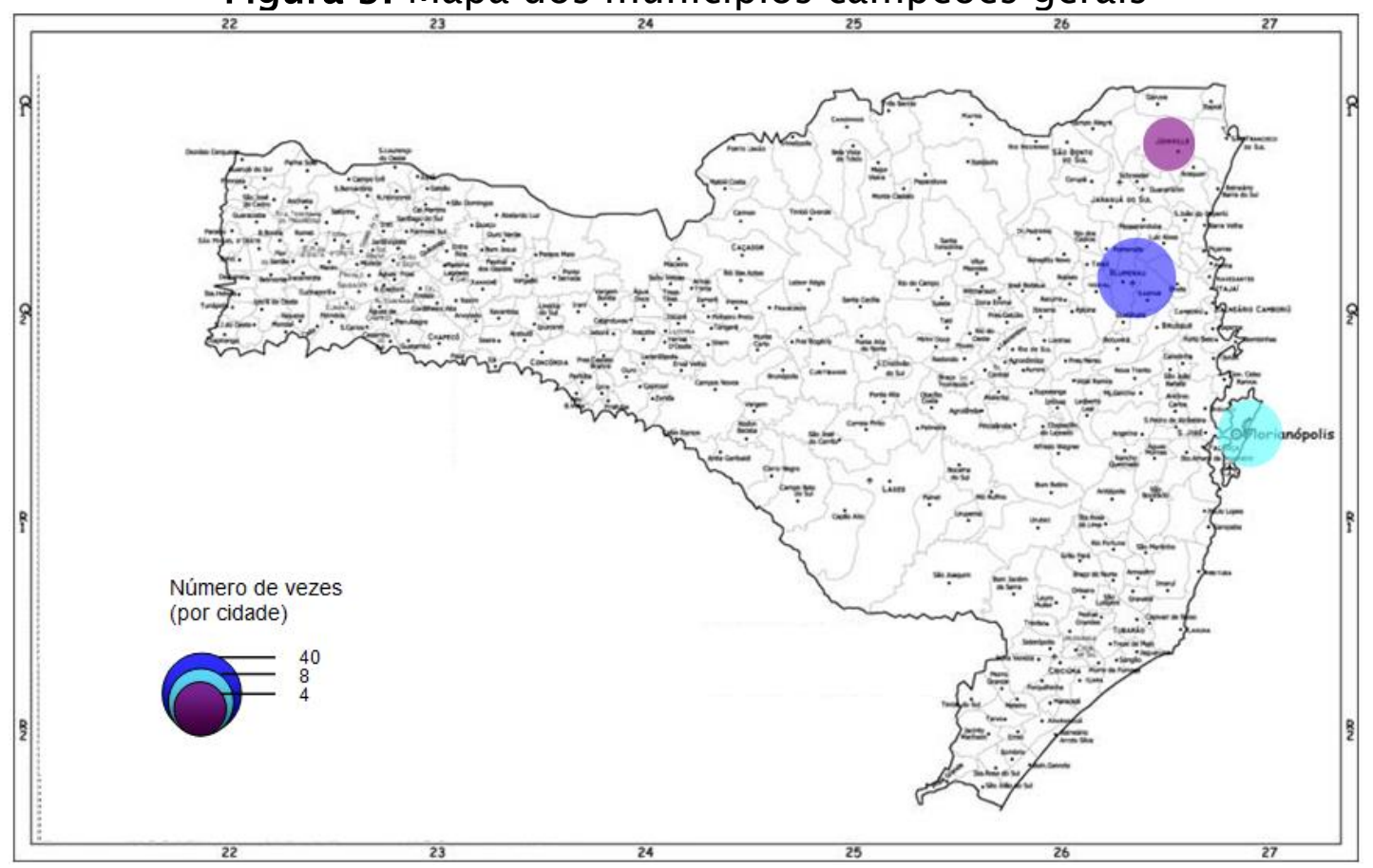

Fonte: adaptado de Casa dos Mapas (2014).

Redes (St. Cruz Sul, Online), v. 20, nº 3 - Suplemento, p. 314 - 340, set./dez. 2015320 
Para dar conta deste problema é preciso observar que as relações entre esporte e território se estabelecem em vários níveis de complexidade. Além disso, o esporte invadiu o espaço público e permite a constituição de redes moveis (GOUGUET, 2004). A economia mundial e a lógica de mercado, por exemplo, estão em constante processo de localização e deslocalização dos polos esportivos. Por isso, um primeiro desafio diz respeito à dificuldade de medição dos impactos do esporte ao território. Essas dificuldades dizem respeito à delimitação territorial, ao fluxo, e a delimitação temporal. Entre os aspectos que mais chamam atenção, destaca-se a localização ótima dos equipamentos esportivos, relativos às desigualdades de acesso etc. Destacam-se também as questões de eficácia do esporte profissional e amador de cada região, no que se refere aos conflitos de usos.

Mas a relação entre esporte e território pode ser invertida e se considerarmos como o esporte configura o território (AUGUSTIN, 1998; MASCARENHAS, 1999). As configurações territoriais do esporte passaram por profundas transformações nas últimas décadas. Essas transformações dizem respeito à incorporação do esporte ao processo de desenvolvimento. Esse processo desemboca numa espécie de partilha esportiva dos territórios, no qual algumas regiões passaram a ser reconhecidas por práticas esportivas específicas. As consequências mais visíveis desse processo dizem respeito ao estabelecimento de territórios esportivos, no qual algumas modalidades agem como fronteiras esportivas. Estes territórios esportivos são delimitados pelos lugares e práticas esportivas que deslocam e acolhem regionalmente.

Para além dos desafios tradicionais, o esporte pode se converter em um demarcador territorial, configurando, assim, novas regionalidades. Os territórios são demarcações que podem ser momentâneas, na medida em que são (re)criadas instituem ritmos e intenções. O esporte não se distribui de forma homogênea no território, por isso a existência de infraestruturas e atividades esportivas revela um fator dominante na configuração do território. Mais precisamente, a sua institucionalização e difusão no campo exprime também os padrões de desenvolvimento regional. Assim, a hierarquia entre localidades nas quais se concentram os JASC indicam uma lógica espacial de organização esportiva. Os resultados nesse processo podem ser 
caracterizados como fronteiras esportivas. Por isso, o esporte também pode ser considerado um demarcador territorial, visto que se espacializa de diferentes formas, demarcado pelos atores sociais e contextos que o estabelecem. Nesse sentido, Raeder (2010, p. 15) salienta que "pensar o território é colocar em causa seus distintos e distintivos usos".

Considerando esses fatores, o presente texto procura examinar as características específicas por meio do qual o esporte amador se territorializa no Estado de Santa Catarina. Argumenta-se que o esporte amador possui uma lógica de territorialização própria e distinta do esporte profissional, e que não acompanha a lógica de diferenciação espacial da produção. O esporte amador necessita de uma rede sociotécnica mais densa que o esporte profissional e, portanto, estabelece uma territorialidade diferente que o esporte profissional. Assim, para desenvolver este argumento, o texto foi dividido em cinco partes principais. Na primeira parte abordaremos as relações entre desenvolvimento regional e território, mostrando como são estabelecidas as demarcações territoriais. Na segunda, dissertamos sobre as concepções de esporte e esporte amador. Na terceira, apresentamos a questão do esporte no contexto catarinense. Na quarta, tratamos das dimensões territoriais dos JASC. Por fim, na quinta parte, são expostas as considerações finais do estudo.

\section{DESENVOLVIMENTO REGIONAL E TERRITORIALIZAÇÃO}

A temática do Desenvolvimento Regional constitui uma expressão que vem ganhando força no meio acadêmico e na opinião pública. Por um lado, a noção de Desenvolvimento Regional constitui um recurso analítico que permite explorar as influências recíprocas que se estabelecem entre as dimensões econômicas, política, ambiental, espacial etc. em nível territorial. A força da ideia de Desenvolvimento Regional reside na articulação de básicas de pesquisa muito distintas, como, por exemplo, a economia, a geografia, a sociologia, a ciência política, a antropologia, etc. A busca de regularidades na relação entre desenvolvimento e região tem feito que, progressivamente, a dimensão regional do desenvolvimento seja estendida para o entendimento de 
novas formas. Nesse sentido, para se pensar as relações entre Desenvolvimento Regional e esporte é preciso ultrapassar os meandros reducionistas e as fragmentações analíticas do conhecimento.

Algumas estratégias de abordagem do Desenvolvimento Regional são advindas do urbanismo, sociologia, ciência política, econômica, administração, geografia, história, dentre outras áreas que se articulam em problemáticas acerca do planejamento urbano e regional. Mais propriamente, a intervenção humana no território e o comportamento social no espaço (BENKO, 1999). Historicamente, a abordagem econômica é a que recebe maior enfoque, centrada na ideia de que crescimento econômico é sinônimo de desenvolvimento. Outra corrente parte da ideia de que desenvolvimento caracteriza-se pela mudança qualitativa no modo de vida das pessoas, nas instituições e nas estruturas produtivas (DALLABRIDA, 2010). Desse modo, faz-se necessário tecer algumas distinções.

Essa é uma questão decisiva no âmbito da pesquisa em Desenvolvimento Regional, na medida em que as discussões na área se localizam quanto às problemáticas de região e território. Lopes (2001) salienta que as regiões não são fechadas. As relações que se estabelecem são objetos de estudo. E esses são aspectos fundamentais para a pesquisa em Desenvolvimento Regional. O todo tem tanta importância quanto as partes (regiões). Para tanto, "importa conhecer as relações entre as partes e o todo; importa conhecer as relações dentro de cada uma das partes; importa conhecer as relações entre as partes" (p. 5). Isso significa que temos algumas proposições para compreender o Desenvolvimento Regional. Nesse estudo, depreendemo-nos ao modelo centrado nas variáveis de tempo e espaço.

Desse modo, consideramos o Desenvolvimento Regional através do processo de mudança. Dallabrida (2010, p. 17) o compreende "como um processo de mudança estrutural, situado histórica e territorialmente, caracterizado pela dinamização socioeconômica e a melhoria da qualidade de vida da sua população". A mudança é estabelecida a partir dos atores materiais e imateriais que incidem sobre o espaço. "O espaço pode definir-se a partir de um conjunto de dados econômicos localizados podendo as localizações ser dispersas, porque o que dá unidade ao espaço são as suas características e a natureza das relações de interdependência" (LOPES, 2001, p. 29). Assim, o estudo do 
Desenvolvimento Regional pode se dar através da matriz analítica (figura 4), expressa na relação entre tempo e espaço que se estabelece sobre o território.

Partimos da assertiva de que o território é um lugar em constante transformação. Essas transformações estabelecem fronteiras, ao mesmo tempo materiais e simbólicas, que operam como demarcadores cognitivos entre o dentro e o fora do território. Por isso, o território pode ser visto como uma rede sociotécnica que associa recursos naturais e sociais mediante convenções de valores e regras, de arranjos institucionais que lhes dão expressão e formas sociais de organização da produção. O desafio deste tipo de abordagem consiste em pensar o território como um conjunto de conexões e fluxos que se constitui através de associações entre natureza e sociedade (MATTEDI, 2014).

Uma das formas de demarcação do território pode ser instituída pela "The laws of form", desenvolvida por Spencer Brown (BROWN, 2011). Para o desenvolvimento da teoria, Spencer aplica os seguintes conceitos: distinção; autoreferência; paradoxo e reentrada. A demarcação é feita através da marca, estabelecida por meio de uma distinção que caracteriza a indicação, ilustrada através do símbolo $\Gamma$. Esse símbolo distingue o que há dentro e fora, estabelecendo a diferença. Portanto, o lado de dentro não é igual ao lado de fora. Por meio de categorias, é possível delinear o que é semelhante e diferente. O conceito de autoreferência permite dissertar sobre um objeto falando do próprio objeto. O paradoxo seria distinguir o próprio objeto. E, por meio da reentrada, distingue-se o objeto a partir dele mesmo.

De modo prático, a noção de forma permite territorializar na medida em que institui uma distinção do que se manifesta em um território e difere no outro. Essa distinção é possível quando se delimita a diferença que permite relacionar ou diferenciar algo. Desse modo, quando sinalizamos a formação de determinado território esportivo, estamos indicando que há outros territórios, que podem ser diferentes ou semelhantes. Diante disso, podemos autoreferenciar esse território esportivo para estabelecer um modo de institucionalização. Os territórios esportivos podem ser estabelecidos através de outra distinção ou através dele mesmo. Dessa forma, estaríamos aplicando os quatro conceitos apresentados por Brown (2011). Esses conceitos nos 
permitem analisar um mesmo objeto por diferentes olhares (MATTEDI, 2014).

Figura 4. Modelo de análise do Desenvolvimento Regional

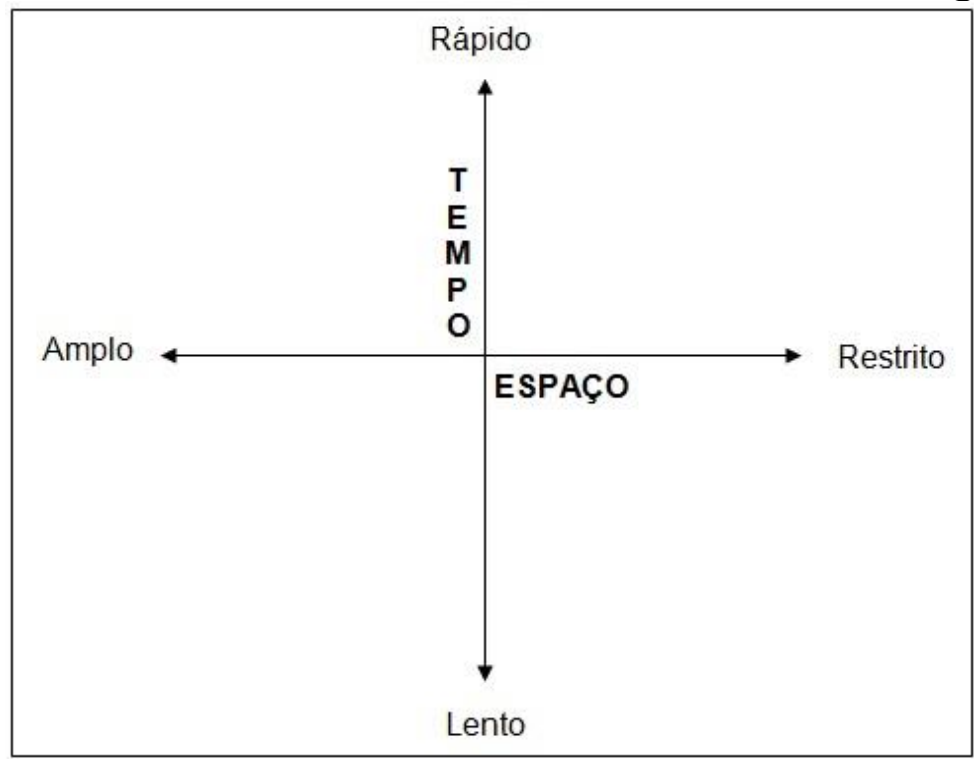

Fonte: elaborado pelos autores da pesquisa.

\section{CONCEPÇÕES DE ESPORTE E ESPORTE AMADOR}

O esporte pode ser visto por diversos ambitos e perspectivas para a sua operacionalização. $O$ esporte desenvolvido nas civilizações antigas tinha o caráter utilitarista de sobrevivência e proteção realizado por meio de práticas não sistematizadas. O esporte instituído nos grandes eventos esportivos com as devidas regras, competições e entidades administrativas é chamado de esporte moderno. Tem suas raízes na Inglaterra em 1820, por meio de Thomas Arnold. Esta forma de sistematização do esporte tem sua ascensão desencadeada pela restauração dos Jogos Olímpicos em 1896 por Pierre Coubertin. Esse movimento olímpico consolidou o esporte e também o amadorismo e o fair play no meio esportivo. Considerando esse processo de consolidação do esporte, podemos pensar a sua espacialização em três ambitos: (1) escolar; (2) participação; (3) rendimento.

O primeiro recorre ao ambiente escolar desenvolvido durante as aulas de Educação Física ou no período contraturno através das escolinhas. O público é composto por indivíduos regularmente matriculados em instituições de ensino de qualquer sistema, da 
educação básica e superior. O esporte é utilizado como ferramenta educacional, sendo utilizado como um bem cultural. Tem como finalidade o desenvolvimento integral do indivíduo, sua formação para o exercício da cidadania e a prática do lazer. Deve, ainda, contribuir para a reflexão sobre o papel do esporte na sociedade. O esporte educacional é praticado nos sistemas de ensino e em formas assistemáticas de educação conforme a Lei 9.394/96-LDB. E é subdividido em esporte de formação e esporte escolar (BRASIL, 1998).

O esporte de participação é aquele desenvolvido durante o tempo ócio, nos momentos de lazer, tendo caráter recreativo. É uma prática voluntária tendo por finalidade contribuir para a integração dos praticantes, promoção da saúde, educação e na preservação do meio ambiente. Para o seu desenvolvimento, não há exigência de regras formais. Durante sua realização, deve prevalecer o sentido lúdico. $O$ lúdico permite a participação de todos e torna o jogo democrático. Por meio dessa vivência os indivíduos devem ter momentos de prazer e satisfação (BRASIL, 1998). O esporte de participação não tem um lugar específico para ser realizado, podendo ocorrer nos diversos âmbitos de espacialização do esporte. Sua institucionalização está relacionada aos processos sociais, não depende estritamente das padronizações esportivas (AUGUSTIN, 1997).

O esporte rendimento é praticado segundo normas e regras de prática desportiva formais, nacionais e internacionais, com a finalidade de obter resultados. O esporte de rendimento se caracteriza como aquela atividade que busca a máxima performance do atleta, visando alcançar e quebrar recordes. É desenvolvido a partir da prática sistemática do treinamento, formação e aperfeiçoamento integral dos atletas. Segue normas dos órgãos esportivos nacionais e internacionais que regulamentam cada modalidade esportiva e são utilizadas pelas respectivas Entidades Nacionais de Administração e de Prática do Esporte. Nesse meio do esporte, há a figura do atleta. Sua operacionalização pode se dar ou não dentro do sistema oficial de administração do esporte (BRASIL, 1998; 2005).

O esporte de rendimento, para o Ministério do Esporte, é subdividido em profissional e não profissional. Os direitos do atleta profissional estão assegurados na Lei 9.615/98 (BRASIL,1998), conhecida como Lei Pelé. Segundo essa lei, o esporte profissional se 
caracteriza pela remuneração pactuada em contrato formal de trabalho entre o atleta e a entidade de prática desportiva. A lei ainda assegura os atletas profissionais quanto às normas trabalhistas e da seguridade social. No esporte não profissional, há inexistência de contrato de trabalho. Desse modo, o que diferencia o atleta profissional do não profissional é o contrato formal de trabalho. Apesar do Ministério do Esporte categorizar o esporte dessa forma, o esporte não profissional, é conhecido, historicamente, como esporte amador.

O esporte amador tem estreita relação com os Jogos Olímpicos. E, sobretudo com o contexto social da Inglaterra. Para os britânicos, poderia praticar esporte aquele que o pratica durante o tempo ócio. Desse modo, havia um mecanismo de controle que restringia a prática esportiva. O esporte ficava restrito somente à aristocracia e à burguesia, afastando os trabalhadores da participação em esportes institucionalizados e dos Jogos Olímpicos. Somente praticavam esportes aqueles que pudessem dedicar-se integralmente e de forma desinteressada (RÚBIO, 2001). O recebimento de pagamento poderia corromper a pureza do esporte. Era disseminada a noção de comportamento cavalheiresco ao esporte, disputado por puro amor ao jogo. Os atletas não poderiam ser pagos ou realizar qualquer tipo de propaganda com a qual pudessem obter lucro (AFIF, 2000).

A profissionalização do esporte representava perigo para os Jogos Olímpicos. A filosofia do amadorismo imperou até os Jogos Olímpicos de 1984, em Los Angeles. Apresentavam-se as práticas esportivas independentes dos poderes públicos, como produto da iniciativa individual e do associacionismo voluntário (RUBIO, 2009). Nessa edição, começou-se a mercantilização do olimpismo e, consequentemente, o crescente poder empresarial (MASCARENHAS, 2011). No Brasil, o profissionalismo e a busca por patrocínio começou a ser realizada no início dos anos 1980 (AFIF, 2000), amparado por uma série de atos legais. Entretanto, atualmente, mesmo não havendo contrato formal de trabalho, é comum atletas e clubes que recebem algum tipo de remuneração. Desse modo, os atletas não possuem qualquer tipo de benefícios designados nas leis trabalhistas.

Os Jogos Olímpicos são considerados competições das mais antigas de caráter amador. Essa representação permaneceu até 1984 . Para os jogos subsequentes, o Comitê Olímpico Internacional retirou 
essa exigência da Carta Olímpica que regulamentava a competição. Essa alteração modificou a dinâmica socioeconômica e política do esporte mundial. Passou a representar uma forma de propagação de poder, apresentando-se como um evento significativo do ponto de vista esportivo, econômico, político, financeiro, comercial, dentre outros (SALLES; SOARES, 2002). As competições tornaram-se pretexto para outros fins, além dos esportivos. Apesar dessas modificações, os Jogos Olímpicos, ainda hoje, são considerados como competição amadora. No Brasil, apesar dos constantes incentivos do governo ao esporte de rendimento, somente no futebol os atletas são considerados profissionais.

O esporte moderno alterou a lógica esportiva. Com o seu desenvolvimento, as práticas começaram a serem sistematizadas e institucionalizadas por entidades administrativas. Nesse período, o esporte até então amador, realizado pela aristocracia e burguesia, espacializa-se e se torna produto mercadológico. Há uma crescente quanto ao número de atletas, clubes, modalidades e instituições que indicam a importância e o prestígio do esporte. Concomitante, o esporte se profissionaliza. Criam-se formas de amparo financeiro aos atletas e aos clubes. Entretanto, a sua lógica permanece amadora. No Brasil, somente o futebol consegue se manter e tornar seus atletas profissionais. Isso demonstra que tornar o esporte profissional requer ir além de atos institucionais e mudanças estruturais.

\section{A FORMACÃO DO ESPORTE AMADOR EM SANTA CATARINA}

Em Santa Catarina, o esporte amador se institui desde o seu processo de colonização. Para entender a realização da competição foco deste estudo, os JASC, é preciso, primeiro, compreender o contexto socioesportivo de Santa Catarina. Para chegar à realização da $1^{\text {a }}$ edição dos JASC, em 1960, é necessário responder às seguintes questões: onde se praticava esporte em Santa Catarina? Quais eram as modalidades praticadas? Quem eram os atletas?

Para responder esses questionamentos, é necessário recorrer ao contexto histórico de Santa Catarina aproximadamente nos anos de 1850. Em razão da vinda dos colonizadores que trouxeram sua tradição, sua cultura e seus costumes. Isto desencadeou formas de organização 
social e, por conseguinte, as manifestações esportivas estão inseridas neste ínterim.

A espacialização do esporte amador em Santa Catarina está relacionada ao processo de ocupação e desenvolvimento da região. Esse processo pode ser dividido em três momentos. (1) A ocupação do litoral catarinense realizada pelos vicentistas e açorianos. (2) No interior do estado, o caminho dos tropeiros. Caminho que ligava o Rio Grande do Sul a São Paulo para a compra e venda de carne e couro na região de Minas Gerais. (3) A colonização realizada às margens do Rio Itajaí-Açu e Itajaí-Mirim pelos europeus (MAAR, PERON, DEL PRÁ NETTO, 2011). Considerando esse processo, a colonização europeia é a que oferece préstimos ao nosso estudo. Nesse movimento de colonização europeia, estabeleceram-se as colônias e, dentro delas, criaram-se as Sociedades.

$\mathrm{Na}$ Alemanha, era comum o associativismo estabelecido por meio das Sociedades de diversas ordens, desde aquelas designadas à proteção dos imigrantes, culturais, sociais, até, propriamente, as desportivas e recreativas. As desportivas e recreativas propiciam o desenvolvimento esportivo no período relacionado. Na cultura alemã, as Sociedades possuíam a função de controlar os lazeres por meio de mecanismos de organização interna, que também refletiam fora do espaço associativo. O associado, para ser aceito na associação, deveria manter uma postura idônea. Nas Sociedades, era onde se organizavam os festejos, competições, reuniões para tratar de assuntos da comunidade, manutenção de suas origens e impedir atividades consideradas promíscuas (FERREIRA; ABREU, 2005). Uma forma de disseminação e ao mesmo tempo controle cultural.

No Estado de Santa Catarina, as Sociedades foram criadas a partir da fundação das colônias. Uma das primeiras colônias foi fundada em 1851 a Colônia Dona Francisca - onde, atualmente, localiza-se o Município de Joinville. Ainda vieram as colônias: Blumenau, em 1850, Florianópolis, nomeada inicialmente colônia de São Pedro de Alcântara, em 1829, e, em 1860, onde hoje se localiza a cidade de Brusque, colônia Itajaí. Nas colônias, por meio das Sociedades, desenvolveram-se diversos elementos próprios da cultura alemã. Desse modo, criaram-se Sociedades de: canto, ginástica, tiro, literárias, de agricultores, dentre outras. Como exemplo, podemos citar: Schützenverein zu Dona Francisca (1855); Sociedade de Canto Helvetia (1856); Deutscher 
Turverein zu Joinville (1858); Schutzenverein Blumenau (1859); dentre outras Sociedades que demarcam a colonização europeia na região (FICKER, 1965).

Nesse movimento de colonização, algumas modalidades esportivas de origem germânica foram desenvolvidas. Na Colônia Dona Francisca, observamos a influência dos alemães no esporte através da ginástica. Foi fundada, em 1858, a Deutscher Turverein zu Joinville (Sociedade Ginástica de Joinville). Os alemães são considerados os precursores dessa modalidade esportiva através do idealizador Friederich Ludwig Jahn. Também desenvolveram aparelhos da ginástica olímpica. Em 1908, foi realizada a festa do Cinquentenário de fundação da Sociedade Ginástica de Joinville e, concomitantemente, competições esportivas de barra fixa; paralelas; cavalo; salto em distância e salto em altura. Posteriormente, desenvolveram-se competições de atletismo, basquete, ginástica, voleibol, punhobol e bolão (SOCIEDADE GINÁSTICA DE JOINVILLE, 1958).

$\mathrm{Na}$ Colônia Blumenau, em 1859, diferente da Colônia Dona Francisca, funda-se o primeiro Schutzenverein Blumenau onde se realizava a manifestação esportiva do tiro. Posteriormente, é construída uma cancha de bolão e, em 1873, é fundada a Sociedade de Ginástica Turnverein. O leque de modalidades práticas na região aumenta para ginástica olímpica, atletismo, natação e jogos esportivos, principalmente o punhobol (PETRY, 1992). Em Desterro (Florianópolis), pelos oficiais da Marinha de Guerra, é fundada, em 1861, a Sociedade de Regatas, onde é desenvolvida a modalidade de remo (MAZO, 2005). Em 1872, com a fundação do Clube Doze de Agosto, desenvolvem-se as modalidades de tiro ao alvo, tênis, bolão, natação e basquete. Na Colônia Itajaí, ainda era praticada a atividade caracterizada como corrida de cavalos, no esporte moderno compreende a modalidade do hipismo (SEYFERTH, 1974).

Em estudo realizado por Costa (1971), sobre o diagnóstico da Educação Física e desporto no Brasil, a região Sul é a que apresenta maior número de Associações desportivas até o ano de 1969, totalizando 127. A região de Santa Catarina, no período de 1931 a 1960, somava 238 Associações desportivas. Pressupomos que isso decorre da influência dos colonizadores alemães nesta região. Nesse processo, o esporte foi se estruturando entre divergências e 
modificações, ao mesmo tempo em que se construía uma elite local, ou seja, aqueles que eram sócios das associações ou clubes e tinham acesso, como por exemplo, a elite formada pelos filhos de comerciantes, agricultores e os próprios comerciantes. Esses, por vezes chamados de ginastas, caracterizavam os atletas que representavam as Sociedades/Associações/Clubes ${ }^{1}$ nas competições esportivas.

Com o desenvolvimento do esporte e a criação de eventos esportivos de grande porte, algumas Sociedades/Clubes se tornam marcantes tanto na criação como manutenção destes (JENICHEN, 1993). A Sociedade Esportiva Bandeirante é uma dessas instituições e será palco da $1^{a}$ edição do JASC. O JASC é uma invenção regional inspirado nos Jogos Abertos do Interior de São Paulo. Segundo Gomes e Fritsche (2010), começou a ser projetado em 1957, quando uma delegação da Sociedade Esportiva Bandeirante, composta por vinte e oito pessoas, representou Santa Catarina no $22^{\circ}$ Jogos Abertos do Interior de São Paulo, custeados pelo empresário e atleta Arthur Schlösser. Entre reuniões e projeções, em 1960, é realizado o JASC junto às festividades de comemoração do Centenário de Brusque.

O esporte amador em Santa Catarina começa a ganhar força e se dissemina por meio das Sociedades, sobretudo de tradição germânica. E relacionado aos fatores de sociabilidade, manutenção da saúde dos indivíduos e do patriotismo. Foram desenvolvidos, inicialmente, aqueles esportes de tradição alemã, como o tiro e a ginástica. Após um período, as Sociedades de Tiro e as Sociedades de Ginástica aumentam o leque de modalidades praticadas e começa-se a criar as competições esportivas. Com o apoio das Sociedades que possuíam infraestrutura e material humano, temos um período de transição no esporte catarinense. É criado uma competição de esporte amador - os JASC que englobam diversas modalidades esportivas sendo disputadas ao mesmo tempo. A partir desse marco no âmbito esportivo, o esporte amador em Santa Catarina irá se (re) estruturar.

\section{AS DIMENSÕES TERRITORIAIS DOS JOGOS ABERTOS DE SANTA CATARINA}

\footnotetext{
1 Em decorrência de momentos históricos de repressão, em alguns períodos se verifica a alteração do nome das Sociedades/Associações/Clubes e até o fechamento.
}

Redes (St. Cruz Sul, Online), v. 20, n 3 - Suplemento, p. 314 - 340, set./dez. 2015331 
O esporte moderno é um fenômeno social de grande visibilidade e possui forte poder de mobilização, sobretudo através dos grandes eventos esportivos. Já foram realizados alguns no Brasil - Jogos Panamericanos (2007), Jogos Mundiais Militares (2011). Iremos, ainda, visualizar isso nos dois próximos grandes eventos esportivos que acontecerão no Brasil. Em 2014, ocorrerá a Copa do Mundo de Futebol, que irá abranger 12 cidades brasileiras. Dois anos depois, teremos as Olimpíadas no Rio de Janeiro. Esses eventos irão influenciar a mobilidade das diversas regiões brasileiras e demarcar um território esportivo. No contexto catarinense, o JASC é a competição esportiva amadora de maior magnitude. Movimenta vários setores antes, durante e após a sua realização. É uma invenção regional, criado em 1960. Anualmente, institucionaliza-se de diferentes formas por atores e contextos diversos.

Nasceu de um anseio pessoal do empresário e atleta Arthur Schlosser, em parceria com colaboradores (GOMES; FRITSCHE, 2010). No decorrer de sua institucionalização, altera a estrutura esportiva no estado, inicialmente, mantido pelos clubes. Tornou-se a competição de maior impacto esportivo catarinense. Durante a competição, a disputa é realizada entre os municípios catarinenses representados por meio das Fundações Municipais de Esporte - FME. Os JASC encontram-se na $55^{\mathrm{a}}$ edição, sendo que, em duas ocasiões - 1983 e 2008 -, foram canceladas devido à ocorrência de fenômenos naturais. Durante seus anos de existência, sua estrutura foi modificada e tornou-se complexa. Considerando este processo, é possível estabelecermos três fases distintas de operacionalização: (1) pioneirismo; (2) consolidação; (3) expansão.

A primeira fase consiste no período que compreende sua institucionalização, tendo a duração de 15 anos (1960-1975). Nesse período, os atletas participantes são cedidos pelos clubes para representar os municípios. Os jogos são organizados pela Comissão Central Organizadora, supervisionada pelo conselho técnico. Em 1970, é criada a Escola Superior de Educação Física e Desportos de Joinville e esta passa a oferecer material humano para a organização da competição. Além disso, a ampliação dos sistemas de ensino superior propicia expertises de diversas áreas que oferecem préstimos ao evento. Em 1969, é criado o título de campeão geral dos JASC, que altera a 
ênfase dada à competição, tornando-a fonte de uso político, ocasionando maior investimento público (GOMES; FRITSCHE, 2010). Ainda nesse período, a competição teve a ascendência de oito para vinte e oito modalidades disputadas (quadro 2$)^{2}$.

A consolidação (1976-1993) é marcada por marcos legais instituídos que determinam ações: iniciando pela homologação da Lei $n^{\circ}$ 5.089 em 1975, que dispõe sobre a organização da Administração Estadual. O desporto e a Educação Física passam para o âmbito da Secretaria da Educação e Cultura do Estado. Mediado por esse ato, em 1976, a realização do JASC passa a ser de responsabilidade do governo estadual. Com isso, a competição é reestruturada e ampliada, criandose as etapas regionais e, posteriormente, em 1983, microrregionais (QUEIROZ, 1990). Contribuindo para a descoberta de talentos, em 1981, a Educação Física torna-se disciplina obrigatória no ensino primário estadual. Em 1984, com o auxílio das tecnologias, foram utilizados pela primeira vez softwares para a realização das inscrições dos municípios (GOMES; FRITSCHE, 2010).

A fase de expansão, instituída a partir de 1994, é marcada pela criação da Fundação Catarinense de Esporte - FESPORTE. A FESPORTE tem a finalidade de projetar e executar a política de desportos do Estado de Santa Catarina. Foi instituída por meio da legislação estadual, assegurada pela Lei $\mathrm{n}^{\circ}$ 9.131, de 1993. Está associada ao Sistema Desportivo Catarinense, legitimado sob a Lei $n^{\circ}$ 9.808, de 1994. O Sistema Desportivo Catarinense compreende a Secretaria de Cultura, Turismo e Esporte - SOL; a FESPORTE; o Conselho Estadual do Esporte CED; o Tribunal de Justiça Desportiva - TJD; as entidades estaduais de administração e prática do desporto e as Federações Desportivas ou equivalentes e seus filiados (SANTA CATARINA, 1994). A FESPORTE é responsável pela realização de eventos esportivos promovidos pelo governo do estado. Entre os eventos, os JASC é o de maior repercussão esportiva em Santa Catarina. $\mathrm{Na} 1^{\text {a }}$ edição, foram disputadas oito modalidades esportivas, sendo que algumas delas nos dois naipes. $\mathrm{Na}$

\footnotetext{
2 A criação das Federações também oferece assistência ao JASC inicialmente chamada Liga Santa Catharina de Desportos Terrestres fundada em 1924. Com a homologação da Lei estadual $n^{\circ}$. 1.611 de 26 de setembro de 1928, é substituída pela Federação Catarinense de Desportos. Com a expansão do esporte, criou-se as diversas Federações que hoje existem, totalizando 56 (CREF, 2014).
} 
Desenvolvimento Regional e Esporte Amador: as dimensões territoriais...

$53^{\mathrm{a}}$ edição, realizada em 2013 , registrou-se vinte e seis modalidades (quadro 2).

Redes (St. Cruz Sul, Online), v. 20, n 3 - Suplemento, p. 314 - 340, set./dez. 2015334 
Quadro 2. Modalidades esportivas nas fases do JASC

\begin{tabular}{|c|c|c|c|c|c|c|}
\hline \multirow{2}{*}{$\begin{array}{l}\text { Ano / Modalidade } \\
\text { Atletismo Masc. }\end{array}$} & \multicolumn{2}{|c|}{$\begin{array}{l}1960-1975 \\
\text { Pioneirismo }\end{array}$} & \multicolumn{2}{|c|}{$\begin{array}{r}1976 \text { - } 1993 \\
\text { Consolidação }\end{array}$} & \multicolumn{2}{|c|}{$\begin{array}{c}1994-2013 \\
\text { Expansão }\end{array}$} \\
\hline & $x$ & $x$ & $x$ & $x$ & $x$ & $x$ \\
\hline Atletismo Fem. & $x$ & $x$ & $x$ & $x$ & $x$ & $x$ \\
\hline Basquete Masc. & $x$ & $x$ & $x$ & $x$ & $x$ & $x$ \\
\hline Basquete Fem. & - & - & - & $x$ & $x$ & $x$ \\
\hline Bocha Rafa Masc. & $x$ & $x$ & $x$ & $x$ & $x$ & $x$ \\
\hline Bocha Rafa Fem. & - & - & - & $x$ & $x$ & $x$ \\
\hline Bolão 16 Masc. & - & $x$ & $x$ & $x$ & $x$ & $x$ \\
\hline Bolão 16 Fem. & - & $x$ & $x$ & $x$ & $x$ & $x$ \\
\hline Bolão 23 Masc.. & - & - & - & $x$ & $x$ & $x$ \\
\hline Bolão 23 Fem. & - & - & - & $x$ & $x$ & $x$ \\
\hline Ciclismo & - & $x$ & $x$ & $x$ & $x$ & $x$ \\
\hline Futebol Masc. & - & - & - & - & - & $x$ \\
\hline Futsal Masc. & - & $x$ & $x$ & $x$ & $\mathrm{x}$ & $x$ \\
\hline Futsal Fem. & - & - & - & $\mathrm{x}$ & - & $x$ \\
\hline G. Olímpica Masc. & - & - & $x$ & $\mathrm{X}$ & $x$ & $x$ \\
\hline G. Olímpica Fem. & - & - & $x$ & $x$ & $x$ & $x$ \\
\hline Ginástica Rítmica & - & - & $x$ & $\mathrm{X}$ & $\mathrm{x}$ & $x$ \\
\hline Handebol Masc. & - & $x$ & $x$ & $x$ & $x$ & $x$ \\
\hline Handebol Fem. & - & $x$ & $x$ & $x$ & $\mathrm{x}$ & $x$ \\
\hline Judô Masc. & - & $x$ & $x$ & $x$ & $x$ & $x$ \\
\hline Judô Fem. & - & - & - & $x$ & $\mathrm{x}$ & $x$ \\
\hline Caratê Masc. & - & - & - & $x$ & $\mathrm{x}$ & $x$ \\
\hline Caratê Fem. & - & - & - & $\mathrm{x}$ & $x$ & $x$ \\
\hline Natação Masc. & $\mathrm{X}$ & $x$ & $x$ & $\mathrm{x}$ & $x$ & $x$ \\
\hline Natação Fem. & $\mathrm{X}$ & $x$ & $x$ & $\mathrm{x}$ & $x$ & $x$ \\
\hline Punhobol & - & $x$ & $x$ & $\mathrm{x}$ & $x$ & $x$ \\
\hline Saltos O. Masc. & $\mathrm{X}$ & $x$ & $x$ & $x$ & - & - \\
\hline Saltos O. Fem. & $\mathrm{X}$ & $x$ & $x$ & $\mathrm{X}$ & - & - \\
\hline Taekwondo Masc. & - & - & - & - & - & $x$ \\
\hline Taekwondo Fem. & - & - & - & - & - & $x$ \\
\hline $\begin{array}{l}\text { Tênis de Campo } \\
\text { Masc. }\end{array}$ & $x$ & $x$ & $x$ & $x$ & $x$ & $x$ \\
\hline $\begin{array}{l}\text { Tênis de Campo } \\
\text { Fem. }\end{array}$ & $x$ & $x$ & $x$ & $x$ & $x$ & $x$ \\
\hline Tênis de Mesa Masc. & - & $x$ & $x$ & $x$ & $x$ & $x$ \\
\hline Tênis de Mesa Fem. & - & $x$ & $x$ & $x$ & $x$ & $x$ \\
\hline $\begin{array}{l}\text { Tiro armas curtas/ } \\
\text { rev. }\end{array}$ & - & $x$ & $x$ & $x$ & $x$ & $x$ \\
\hline $\begin{array}{l}\text { Tiro armas longas/ } \\
\text { car. }\end{array}$ & - & $x$ & $x$ & $x$ & $x$ & $x$ \\
\hline
\end{tabular}




\begin{tabular}{|c|c|c|c|c|c|c|}
\hline Tiro ao prato & - & $\mathrm{X}$ & $\mathrm{X}$ & $\mathrm{X}$ & $\mathrm{x}$ & $x$ \\
\hline Tiro pombo & - & $\mathrm{X}$ & $X$ & - & - & - \\
\hline Triathlon Masc. & - & - & - & - & - & $x$ \\
\hline Triathlon Fem. & - & - & - & - & - & $x$ \\
\hline Voleibol Masc. & $x$ & $\mathrm{X}$ & $\mathrm{X}$ & $x$ & $x$ & $\mathrm{X}$ \\
\hline Voleibol Fem. & $x$ & $\mathrm{X}$ & $\mathrm{X}$ & $x$ & $x$ & $\mathrm{x}$ \\
\hline $\begin{array}{l}\text { Vôlei de Duplas } \\
\text { Masc. }\end{array}$ & - & - & - & - & - & $x$ \\
\hline Vôlei de Duplas Fem. & - & - & - & - & - & $\mathrm{X}$ \\
\hline Xadrez Masc. & $x$ & $\mathrm{X}$ & $x$ & $\mathrm{x}$ & $\mathrm{X}$ & $\mathrm{X}$ \\
\hline Xadrez Fem. & - & $\mathrm{X}$ & $x$ & $x$ & $\mathrm{X}$ & $\mathrm{X}$ \\
\hline Remo Masc. & - & - & - & $\mathrm{x}$ & $\mathrm{X}$ & $\mathrm{X}$ \\
\hline Remo Fem. & - & - & - & - & - & $X$ \\
\hline $\begin{array}{ll}N^{\circ} \quad \text { total de } \\
\text { modalidades }\end{array}$ & 8 & 19 & 21 & 23 & 22 & 26 \\
\hline
\end{tabular}

Fonte: adaptado de FESPORTE (2014).

Os JASC de 2012 movimentaram, aproximadamente, seis milhões de reais na economia local de Caçador, cidade sede do evento (figura 5). Envolveram $7 \mathrm{mil}$ pessoas, entre atletas, dirigentes, árbitros e profissionais da organização do evento, número que representa $10 \%$ da população do município, que conta com quase 70 mil habitantes. Isso demonstra o impacto e o legado que um evento esportivo de grande porte realiza na cidade sede do evento (quadro 3). São construídas e reformadas as estruturas esportivas, como ginásios e quadras, para comportar a competição (DIÁRIO CAÇADORENSE, 2013). Na 53ª edição, realizada em Blumenau, é somada a participação de 177 municípios, incluindo as três etapas da competição; o que equivale a $60 \%$ do total de municípios do Estado. Na fase final, estimou-se a participação de cerca de 5 mil atletas que disputaram as 26 modalidades (FESPORTE, 2013). 
Figura 5. Cidades que sediaram o JASC

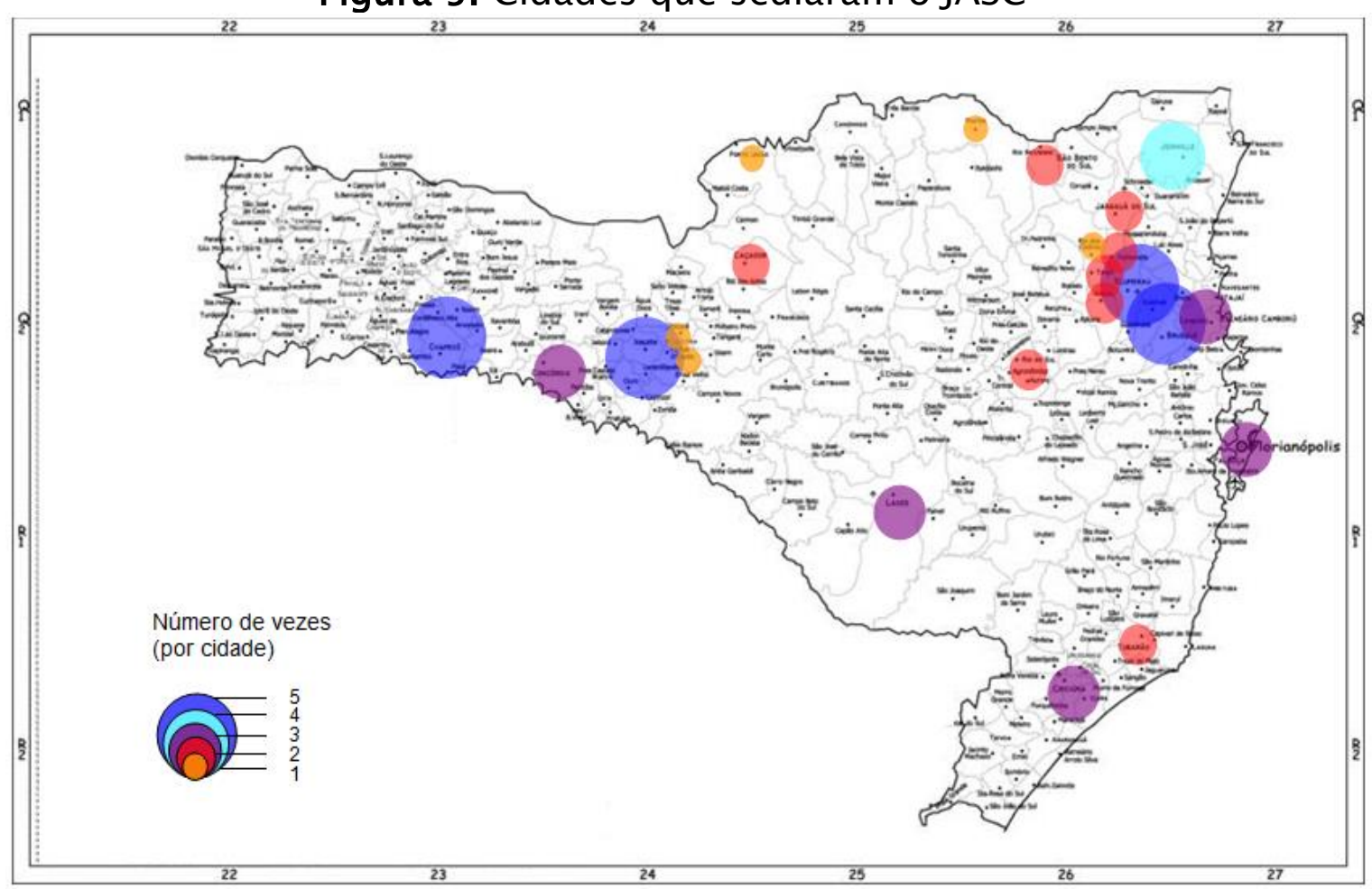

Fonte: adaptado de Casa dos Mapas (2014). 
Desenvolvimento Regional e Esporte Amador: as dimensões territoriais...

Quadro 3. Ano, edição e cidade sede do JASC

\begin{tabular}{|c|c|c|}
\hline Ano & Edição & Cidade Sede \\
\hline 1960 & $1^{a}$ & Brusque \\
\hline 1961 & $2^{a}$ & Florianópolis \\
\hline 1962 & $3^{a}$ & Blumenau \\
\hline 1963 & $4^{a}$ & Joinville \\
\hline 1964 & $5^{a}$ & Porto União \\
\hline 1965 & $6^{a}$ & Brusque \\
\hline 1966 & $7^{\mathrm{a}}$ & Lages \\
\hline 1967 & $8^{a}$ & Joaçaba \\
\hline 1968 & $9^{a}$ & Mafra \\
\hline 1969 & $10^{\mathrm{a}}$ & Joinville \\
\hline 1970 & $11^{\mathrm{a}}$ & Concórdia \\
\hline 1971 & $12^{\mathrm{a}}$ & Rio do Sul \\
\hline 1972 & $13^{\mathrm{a}}$ & Itajaí \\
\hline 1973 & $14^{\mathrm{a}}$ & São Bento do Sul \\
\hline 1974 & $15^{\mathrm{a}}$ & Criciúma \\
\hline 1975 & $16^{\mathrm{a}}$ & Chapecó \\
\hline 1976 & $17^{\mathrm{a}}$ & Tubarão \\
\hline 1977 & $18^{\mathrm{a}}$ & Florianópolis \\
\hline 1978 & $19^{a}$ & Caçador \\
\hline 1979 & $20^{\mathrm{a}}$ & Blumenau \\
\hline 1980 & $21^{\mathrm{a}}$ & Jaraguá do Sul \\
\hline 1981 & $22^{\mathrm{a}}$ & Lages \\
\hline 1982 & $23^{a}$ & Itajaí \\
\hline 1983 & $24^{\mathrm{a}}$ & Não realizado* \\
\hline 1984 & $25^{\mathrm{a}}$ & Concórdia \\
\hline 1985 & $26^{a}$ & Brusque \\
\hline 1986 & $27^{\mathrm{a}}$ & Joinville \\
\hline 1987 & $28^{\mathrm{a}}$ & Criciúma \\
\hline 1988 & $29^{a}$ & Joaçaba \\
\hline 1989 & $30^{\mathrm{a}}$ & Joaçaba \\
\hline 1990 & $31^{\mathrm{a}}$ & Blumenau \\
\hline 1991 & $32^{\mathrm{a}}$ & Chapecó \\
\hline 1992 & $33^{\mathrm{a}}$ & Joinville \\
\hline 1993 & $34^{\mathrm{a}}$ & Tubarão \\
\hline 1994 & $35^{\mathrm{a}}$ & Florianópolis \\
\hline 1995 & $36^{\mathrm{a}}$ & Rio do Sul \\
\hline 1996 & $37^{\mathrm{a}}$ & São Bento do Sul \\
\hline 1997 & $38^{\mathrm{a}}$ & Concórdia \\
\hline 1998 & $39^{a}$ & Joaçaba \\
\hline 1999 & $40^{\mathrm{a}}$ & Chapecó \\
\hline 2000 & $41^{\mathrm{a}}$ & Brusque \\
\hline 2001 & $42^{\mathrm{a}}$ & Itajaí \\
\hline 2002 & $43^{a}$ & Lages \\
\hline
\end{tabular}




\begin{tabular}{|c|c|c|}
\hline 2003 & $44^{\mathrm{a}}$ & Blumenau \\
\hline 2004 & $45^{\mathrm{a}}$ & Pomerode, Indaial e Timbó \\
\hline 2005 & $46^{\mathrm{a}}$ & Chapecó \\
\hline 2006 & $47^{\mathrm{a}}$ & Joaçaba, Herval d' Oeste e Luzerna \\
\hline 2007 & $48^{\mathrm{a}}$ & Chapecó \\
\hline 2008 & $49^{\mathrm{a}}$ & Cancelado* \\
\hline 2009 & $50^{\mathrm{a}}$ & Chapecó \\
\hline 2010 & $51^{\mathrm{a}}$ & Brusque \\
\hline 2011 & $52^{\mathrm{a}}$ & Criciúma \\
\hline 2012 & $53^{\mathrm{a}}$ & Caçador \\
\hline 2013 & $54^{\mathrm{a}}$ & Blumenau \\
\hline
\end{tabular}

Fonte: adaptado de FESPORTE (2014).

A partir de 1969, com a criação do título geral, as grandes cidades visualizam na competição uma forma de forte apelo político e vislumbram a conquista do título geral como veículo midiático. As cidades que anualmente figuram na disputa pela conquista do título geral dos jogos possuem o maior PIB $^{3}$ de Santa Catarina: Joinville, Florianópolis, Itajaí e Blumenau. Blumenau é o maior ganhador, soma 40 títulos conquistados. Essas cidades possuem projetos de iniciação esportiva subsidiados pelo governo federal, o que contribui para a continuidade do trabalho. E ainda, geralmente, possuem times que representam as FMEs e disputam competições nacionais por clubes e/ou associações que financiam atletas de alto nível, o que permite a captação de verbas do governo por meio de projetos.

Como observamos até o momento, há uma série de fatores e atores que envolvem a utilização do esporte e a realização de uma edição dos JASC. Isso demonstra os fatores atrelados a aspectos econômicos, políticos, institucionais, técnicos, culturais, dentre outros. Elencamos adiante dez grupos de atores que interligados estabelecem associações que se mantêm, sustentam e dissolvem em um contexto de reciprocidade composta pela interação de todos os envolvidos. Diversas associações instituem-se para a consolidação da competição, o que explicita que diferentes atores são necessários para o desenvolvimento do evento. Segundo Harman (2009, p. 17), são as alianças que

\footnotetext{
3 Segundo a Secretaria de Estado do Planejamento, as cidades que tem o maior PIB em Santa Catarina são Joinville, Florianópolis, Itajaí e Blumenau. Dados disponíveis em: $<$ http://www.spg.sc.gov.br/dados_munic.php\#pibmunicipal $>$.
} 
fortalecem os atores e são as relações que identificam os atores, "um ator é suas relações".

Na figura 6, a seguir, apresentamos os dez grupos de atores, a saber: (1) estado - representa o poder público como promotor do evento através da SOL e da FESPORTE; (2) fundações - municípios e sua delegação; (3) federações - material humano capacitado para gerir as modalidades específicas; (4) empresas - subsídio através dos materiais esportivos, premiação, alimentação; (5) modalidades esportivas compreendem os esportes disputados; (6) locais de competição - locais específicos para o desenvolvimento das modalidades; (7) infraestrutura - espaços necessários que extrapolam o ambiente propriamente esportivo; (8) mídia - visibilidade ao evento; (9) público alvo interessados no evento; (10) patrocinadores - financiam e ao mesmo tempo promovem a competição. 
Figura 6. Rede de atores humanos e não humanos dos JASC

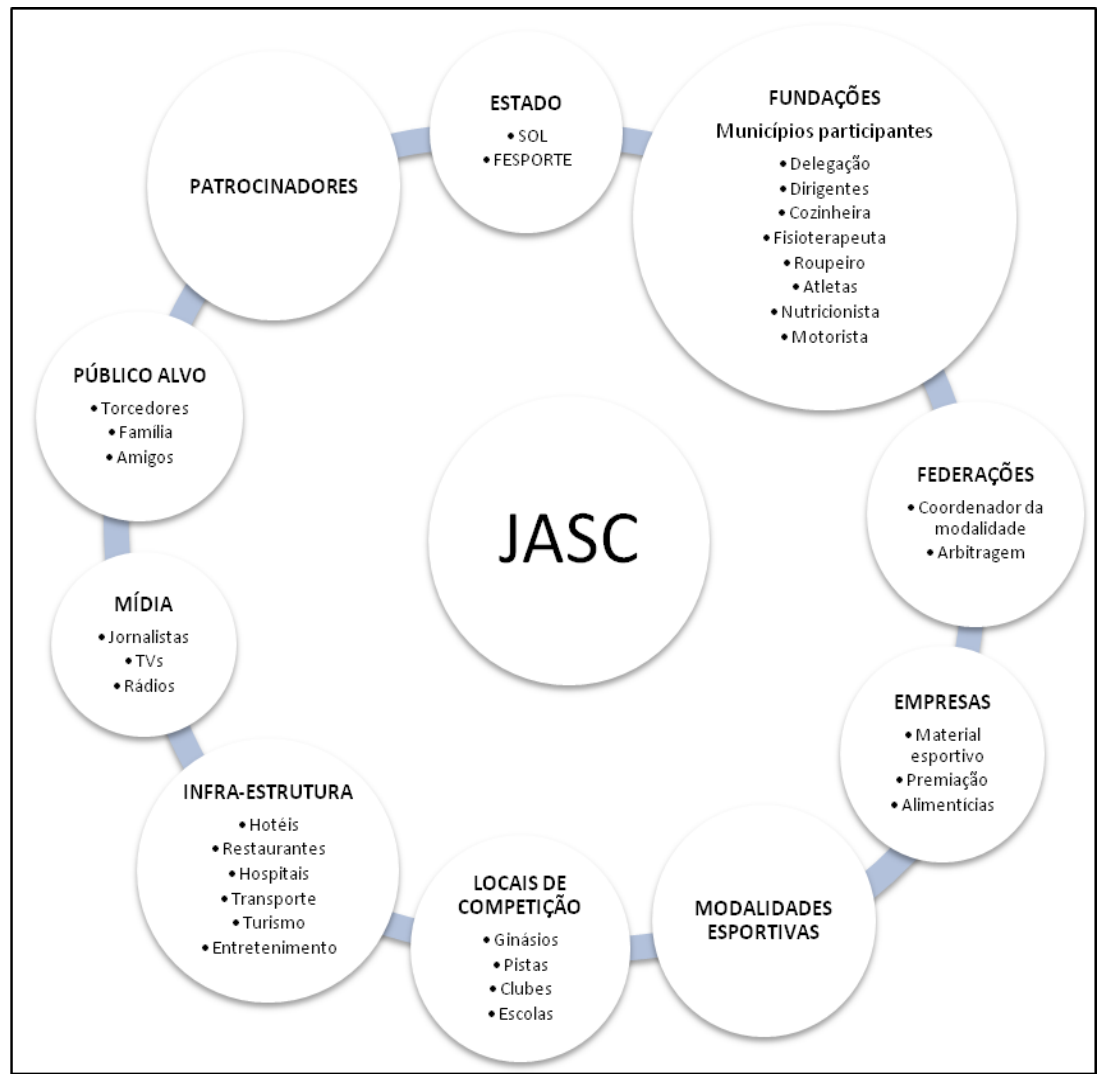

Fonte: elaborado pelos autores da pesquisa.

O desenvolvimento do esporte durante as 53 edições já realizadas dos JASC causa algumas controvérsias. Inicialmente era utilizado como meio de sociabilidade e se torna ato político, com isso, altera as relações sociais na produção do contexto social, sua estrutura se complexifica e o torna mais denso. Devido a sua estrutura, mesmo designado como um evento amadorístico, é reflexo do sistema profissional. Desse modo, mobiliza, alinha e opera conhecimentos e expertises de diversas áreas do conhecimento. Além de modificações na estrutura operacional, observa-se o crescimento do número de universidades, hoje são 29 instituições que oferecem curso de Educação Física presencial e, ainda, duas instituições apresentam curso à distância, totalizando 78 cursos em atividade (que envolvem bacharelado e licenciatura). Esse fato que contribui para o aumento do nível técnico e a própria organização do evento. Considerando esse processo, os JASC são produto de um fenômeno social mediado pelas associações entre seus atores. 
Os cursos de Educação Física concentram-se, inicialmente, nos municípios de Joinville, Florianópolis, Criciúma e Blumenau e, posteriormente, expandem-se por todo o estado. O primeiro curso foi instituído em 1970, na hoje denominada Universidade da Região de Joinville - UNIVILLE. Naquela ocasião, criou-se o curso de Licenciatura. Entre 1973 e 1975, criam-se os cursos no Município de Florianópolis. Em 1973, na Universidade do Estado de Santa Catarina -UDESC. e em 1975, na Universidade Federal de Santa Catarina - UFSC. Ambos para formação de licenciados. Em 1974, surge o curso de licenciatura em Educação Física na Universidade do Extremo Sul Catarinense - UNESC. Também em 1975, no Município de Blumenau na Universidade Regional de Blumenau - FURB, para a formação de bacharéis e licenciados. De acordo com as políticas nacionais vigentes na época, esses cursos formavam apenas licenciados, o que causa uma contradição quanto ao curso de bacharelado da FURB visto que ainda não havia curso de bacharelado. Todavia, apresentamos os dados cadastrados na plataforma e-MEC.

Esses foram os cinco primeiros cursos de graduação em Educação Física no estado. Surgem no período caracterizado como pioneirismo (1960 - 1975) dos JASC e oferecem subsídios para a competição. Em seguida, no período de consolidação do evento, que compreende de 1976 a 1993, há uma fase de estabilização. Somente um curso de Educação Física é criado na Universidade do Contestado - UNC, no Município de Concórdia, no ano de 1989. Após esse período, apenas no ano de 1995 é criado um novo curso já no período de expansão dos JASC, que tem início em 1994. Essa fase de estabilização e poucos cursos pode indicar que não havia uma demanda por meio do mercado de trabalho e/ou a não existência de fiscalização que permitia o trabalho sem habilitação profissional (COSTA, 1971).

A partir do ano de 1995, há uma fase de ascensão e são criados 67 novos cursos de graduação em Educação Física. O ano de 2008 é o que soma a maior quantidade de novos cursos, totalizando 13. No período de 1996 a 1998 nenhum novo curso entra em funcionamento. Apesar do pioneirismo da UFSC e UDESC, após os anos de 1975 e 1973, respectivamente anos de início do funcionamento do curso nessas instituições, não houve novos polos sendo abertos. Somente em $2006 \mathrm{e}$ 2008 foi instituída a oferta de cursos de bacharelado. Isso salienta a 
predominância de cursos privados ou públicos de caráter privado (cursos pagos oferecidos pelas universidades comunitárias). Lembramos que cinco cursos não são contabilizados (quatro de licenciatura e um de bacharelado), pois na plataforma do e-MEC não consta a data de início de funcionamento. Supomos que os cursos que não consta a data de início do funcionamento obtiveram a autorização do MEC para oferta do curso, entretanto, ainda não iniciaram nenhuma turma.

Os cursos de Educação Física estão dispersos por todo o estado. Sendo que os municípios de Florianópolis, Chapecó, Blumenau, Joinville, Pinhalzinho, Criciúma, Tubarão e Lages comportam o maior número de instituições de ensino superior que oferecem curso de Educação Física. Há a preponderância e concentração de instituições na região litorânea. No Município de Florianópolis, existem três instituições, a UFSC, UDESC e o Instituto de Ensino superior da Grande Florianópolis - IESGF e em Chapecó, Universidade do Oeste de Santa Catarina - UNOESC, Universidade Comunitária da Região de Chapecó - UNOCHAPECÓ e Faculdade Exponencial - FIE. Já em Blumenau, FURB e Faculdade Metropolitana de Blumenau - FAMEBLU; em Joinville, UNIVILLE e Instituto Superior e Centro Educacional Luterano - IELUSC; em Pinhalzinho, Faculdade Pinhalzinho - HORUS e UNOESC; em Criciúma, Escola Superior de Criciúma - ESUCRI e UNESC; em Lages, Centro Universitário FACVEST - FACVEST e Universidade do Planalto Catarinense - UNIPLAC. Em cada um desses municípios há duas instituições. Atualmente, 29 municípios no estado possuem cursos para formação de profissional em Educação Física (e mais duas instituições que oferecem o curso a distância).

Os municípios que somam o maior número de cursos em funcionamento são Florianópolis, Blumenau e Chapecó. Esses municípios possuem seis cursos em funcionamento cada, divididos entre bacharel e licenciatura. O município de Lages soma cinco cursos em funcionamento. Seguido dos municípios de Joinville, Pinhalzinho e Criciúma, que possuem quatro cada um. Esses dados das instituições e do número de cursos em funcionamento indicam a descentralização e distribuição dos cursos de Educação Física em Santa Catarina. O que salienta a dispersão e consequente oportunidade de acesso a essa formação profissional pela população dos municípios. Entretanto, apesar da distribuição das instituições no estado, em algumas localidades, observa-se a inexistência de instituições. Isso acarreta a 
busca pelo conhecimento e o deslocamento para os municípios mais próximos.

Desde o ano de 1939 até 2014, há a expansão dos cursos de graduação em Educação Física no que se refere à quantidade, tanto em números como em instituições que oferecem essa modalidade de formação. A respeito da forma de espacialização territorial, as instituições se distribuem em diversos municípios do estado, mesmo que, em alguns locais, observa-se maior concentração de instituições, contrapondo, por exemplo, a forma de espacialização dos municípios que conquistam o título de campeão geral dos JASC. Efetiva-se a dispersão de instituições de ensino superior. Todavia, também preponderam instituições na faixa litorânea do estado. Nesse sentido, sinalizamos os possíveis préstimos que a educação de ensino superior oferece ao Sistema Desportivo Catarinense, sobretudo aos JASC, a partir da formação de profissionais qualificados para as diversas áreas de atuação.

Os cursos de graduação em Educação Física são ponto fundamental na rede dos JASC. Necessários, mas não suficientes para o desenvolvimento dos JASC. Observa-se que, para o desenvolvimento da competição e, consequentemente, a conquista do título de campeão geral, outras variáveis influenciam além das instituições de ensino superior. Como exemplo, podemos citar o Município de Criciúma que, apesar de ser um dos pioneiros na implantação do curso de Educação Física, não conquistou o título de campeão geral. Essa evidência sinaliza que, para o desenvolvimento dos JASC, é necessária uma rede mais densa subsidiada por diversos atores.

\section{CONSIDERAÇÕES FINAIS}

O esporte possui uma relação direta com o Desenvolvimento Regional. A crescente centralidade do esporte na sociedade moderna revela que o esporte polariza o espaço em função das regiões mais desenvolvidas, mais precisamente nas regiões mais desenvolvidas. Esse processo está relacionado não somente à localização da infraestrutura esportiva, à fixação dos equipamentos, mas diz respeito também às modalidades esportivas difundidas e praticadas em cada local. Em função desse processo, os resultados esportivos em termos de 
rendimento competitivo exprimem essa hierarquia. Isso indica que as modalidades desportivas praticadas variam territorialmente.

A sistematização do esporte moderno está relacionado aos países europeus. É demarcado pela padronização das manifestações esportivas através de regulamentações que determinam a sua institucionalização. No contexto catarinense, o esporte se espacializa através do processo de colonização europeia. O território esportivo catarinense tem uma lógica própria de espacialização. Os JASC são demarcados por alguns períodos que se diferenciam devido ao modo de operacionalização. Esses dependem de atos políticos dos governantes, intencionalidades empresariais, do grau de conscientização e mobilização da sociedade, sobretudo local, instituições do ensino superior e orçamento público. A partir disso, identificamos que, por trás do esporte amador mediado pela organização dos JASC, há uma série de atores humanos e não humanos que o determinam.

Para a conquista do título geral da competição, há a necessidade de uma rede mais extensa. Por meio do processo de territorialização chegamos a alguns pressupostos que diferenciam os três municípios que possuem a hegemonia do título geral: (1) o contexto cultural e histórico de ocupação; (2) o processo de atração de atletas pela existência de cursos de graduação em Educação Física; (3) o orçamento destinado ao esporte das FMEs é maior; (4) são as cidades mais populosas do estado. Além disso, a região litorânea sediou mais vezes os JASC atraindo maior investimento público em nível estadual e municipal. Esses são alguns dos pontos que estabelecem o polo de concentração do esporte na região litorânea. Desse modo, percebe-se que, ao contrário do esporte profissional, o esporte amador não é determinado unicamente pelas regiões mais desenvolvidas economicamente.

A lógica do esporte amador difere do esporte profissional territorialmente. No esporte profissional, há maior investimento privado, por meio de patrocínios, do que público. Ao contrário do esporte profissional, o esporte amador não depende, sobretudo, das relações de patrocínio, pois recebe investimento municipal. A lógica amadora é subsidiada pelo setor público. Percebe-se uma relação inversa entre esporte amador e esporte profissional dos subsídios que o gerenciam. $\mathrm{O}$ esporte profissional recebe maior montante de investimento privado do 
que público, sobretudo porque o futebol possui maior popularidade e o campeonato tem longa duração, atraindo a mídia por maior período. Por outro lado, a competição amadora, a exemplo, os JASC, tem curta duração. Dito de outra forma, o esporte amador necessita de uma maior ancoragem territorial.

\section{REFERENCIAS}

AFIF, Antônio. $A$ bola da vez: o marketing esportivo como estratégia de sucesso. São Paulo: Infinito, 2000.

AUGUSTIN, Jean-Pierre. Les territoires émergents du Sport. Le Revue de la Communication, Quaderni n. 34, 1998, pp.129-140.

AUGUSTIN, Jean-Pierre. Les Territoires Incertains du Sport. Cahiers de Géographie, n. 114, v. 41, 1997. pp. 405-411.

BENKO, Georges. A ciência regional. Oeiras: Celta, 1999.

BRASIL. Lei n. $^{\circ} 9.615$, de 24 de março de 1998. Institui normas gerais sobre o desporto e dá outras providências. Brasília: Imprensa Nacional, 1998.

BRASIL. Lei $\mathrm{n}^{\circ}$ 9.615, de 24 de março de 1998. Institui normas gerais sobre desporto e dá outras providências. Disponível em: <http://www.planalto.gov.br/ccivil_03/leis/19615consol.htm>. Acesso em: 22 jan 2014.

BRASIL. Ministério do Esporte. Resolução n ${ }^{\circ}$, de 14 de junho de 2005. Aprova a Política Nacional do Esporte. Diário Oficial [da] República Federativa do Brasil, Brasília, DF, p. 128-132, 16 ago. 2005.

BROWN, Spencer. The laws of form. Warminster: Bohmeier Verlag, 2011.

CASA DOS MAPAS. Mapa de Santa Catarina. Disponível em: <http://www.casadosmapas.com.br/imagem/cartogramas/sc.jpg >. Acesso em: 10 maio 2014. 
CEAG. Evolução histórico-econômica de Santa Catarina: estudo das alterações estruturais (século XVII - 1960). Florianópolis: Centro de Assistência Gerencial de Santa Catarina, 1980.

CREF.

Federações.

Disponível

em:

$<$ http://www.crefsc.com.br/index2.php?id_conteudo=14>. Acesso em: 10 fev. 2014.

COSTA, Lamartine Pereira da. Diagnóstico de Educação Física e desportos no Brasil. Rio de Janeiro: MEC, FENAME, 1971.

DALLABRIDA, Valdir Roque. Desenvolvimento regional: por que algumas regiões se desenvolvem e outras não?. Santa Cruz do Sul: EDUNISC, 2010.

DIÁRIO CAÇADORENSE. Jasc injetam $R \$ 6$ milhões na economia local. Caçador. Disponível em: <http://www.diariocacadorense.com/noticiasdetalhes. php?id=3573>. Acesso em: 10 dez. 2013.

EDITORA LETRAS BRASILEIRAS. 2014. Disponível em: <http://www.santacatarinaturismo.com.br/cms/dbarquivos/dbanexos/ 921662cb644c6767e0bb99fc0da529da.jpg >. Acesso em: 20 fev. 2014.

FIESC. Santa Catarina em Dados. Unidade de Política Econômica e Industrial. - Florianópolis: FIESC, 2013.

FERREIRA, Cristina; ABREU, Anne Caroline Peixer. Os clubes de caça e tiro após a Segunda Guerra Mundial em Blumenau. Blumenau em cadernos, Blumenau, n. 11/12, p. 65 - 87, dez. 2005.

FESPORTE. $53^{\circ}$ JASC terá participação de atletas de 177 cidades. Disponível em: $<$ http://www.fesporte.sc.gov.br/index.php?option=com_content\&view= article\&id $=1544: 530$-jasc-tera-participacao-de-atletas-de-177cidades\&catid=323: noticias\&ltemid=575>. Acesso em: 10 dez. 2013. 
FESPORTE. Jogos Abertos (JASC). Disponível em: $<$ http://fesporte.sc.gov.br/consultas/documentos-indice/category/3jogos-abertos-jasc >. Acesso em: 20 fev. 2014.

FICKER, Carlos. História de Joinville: subsídios para a crônica da Colônia Dona Francisca. 2. ed. Joinville : [sn.], 1965.

GOMES, Marco Aurélio; FRITSCHE, Valmor. JASC 50 anos: história de vencedores. Florianópolis: ACAERT, 2010.

GOUGUET, Jean-Jacques. Sport et territoire: un état des lieux, Revue Juridique et Economique du Sport, n. 70, Mars 2004.

GOULARTI FILHO, Alcides. Formação econômica de Santa Catarina. 2. ed. rev. Florianópolis: Ed. da UFSC, 2007.

HARMAN, G. Irreductions. In: HARMAN, G. Prince of networks: Bruno Latour and metaphysics. Melbourne: Re.press, 2009. p. 11-32.

HERING, Maria Luiza Renaux. Colonização e indústria no Vale do Itajaŕ: o modelo catarinense de desenvolvimento. Blumenau: Ed. da FURB, 1987.

IBGE. Santa Catarina. Disponível em: $<$ http://www.ibge.gov.br/estadosat/perfil.php?lang=\&sigla=sc $>$. Acesso em: 10 novembro 2013.

JENICHEN, Oscar. Ipiranga 100 anos: 1893-1993. Florianópolis: Paralelo 27, 1993.

LATOUR, Bruno. Reassembling the Social: An Introduction to ActorNetwork-Theory. New York, NY: Oxford University. Press, 2005.

LOPES, Antônio Simões. Desenvolvimento regional: problemática, teoria, modelos. Lisboa: Fundação Calouste Gulbenkian, 2001. 
MAAR, Alexander; PERON, André; DEL PRÁ NETTO, Fernando. Santa Catarina: história, espaço geográfico e meio ambiente. 2. ed. rev e ampl. Florianópolis: Insular, 2011.

MASCARENHAS, Gilmar. Desenvolvimento urbano e os grandes eventos esportivos: o legado olímpico nas cidades. In: MASCARENHAS, G.; BIENENSTEIN, G.; SÁNCHEZ, F. (Org.). O jogo continua: megaeventos esportivos e cidades. Rio de Janeiro: Eduerj - Faperj, 201 1, p. 27-39.

MATTEDI, Marcos Antônio. Pensando com o desenvolvimento regional: subsídios para um programa forte em desenvolvimento regional. Revista Brasileira de Desenvolvimento Regional, v. 2, p. 59-105, 2014.

MAZO, Giovana Zarpellon. Clubes e sociedades esportivas das cidades de Florianópolis, Blumenau e Joinville, SC. In: Lamartine da Costa. (Org.). Atlas do Esporte no Brasil. Rio de Janeiro: SHAPE, 2005. p. 202-204.

PETRY, Sueli Maria Vanzuita. Os clubes de caça e tiro na região de Blumenau, 1859-1981. Blumenau: Fundação Casa Dr. Blumenau, 1982.

RAEDER, Sávio. Jogos e cidades: ordenamento territorial urbano em grandes eventos esportivos. Brasília: Ministério do Esporte, 2010.

RAUD, Cécile. Indústria, território e meio ambiente no Brasil: perspectivas da industrialização descentralizada a partir da análise da experiência catarinense. Florianopolis: Ed. da UFSC; Blumenau: Ed. da FURB, 1999.

RUBIO, Kátia. Esporte e juventude: privilégio ou direito? De todos ou dos habilidosos?. In: ESPINDULA, B. (org.) Políticas de esporte para a juventude: contribuições para debate. São Paulo: Centro de Estudos e Memória da Juventude: Instituto Pensarte, 2009.

RUBIO, Kátia. O imaginário esportivo contemporâneo: o atleta e o mito do herói. São Paulo: Casa do Psicólogo, 2001. 
SALLES, José Geraldo do Carmo; SOARES, Antônio Jorge G. Evolução da concepção do amadorismo no Movimento Olímpico Internacional: uma aproximação conceitual. In.: TURINI, Marcio; DaCOSTA, Lamartine (orgs.). Coletânea de textos em estudos olímpicos. Rio de Janeiro: Editora Gama Filho, 2002. p. 851-867.

SANTA CATARINA. LEI n. ${ }^{\circ}$ 9.808, de 26 de dezembro de 1994. Publicada no Diário Oficial n. ${ }^{\circ} 15.088$, de 26.12.94. Cria o Sistema Desportivo Estadual de Santa Catarina em consonância com o Art. 15 da Lei Federal n. ${ }^{\circ}$ 8.672, de 06 de julho de 1.993 e institui normas gerais sobre desportos e dá outras providências. Disponível em: <http://www3.sol.sc.gov.br/fesporte/fesporte/leis_estadual/9808.htm >. Acesso em: 10 jul. 2013.

SEYFERTH, Giralda. A colonização alemã no Vale do Itajai-Mirim: um estudo de desenvolvimento econômico. Porto Alegre : Movimento, 1974.

SIEBERT, Claúdia Freitas. Desenvolvimento regional em Santa Catarina. Blumenau: Edifurb, 2001.

SOCIEDADE GINÁSTICA DE JOINVILLE 1858-1958. Joinville: Sociedade Ginástica de Joinville, 1958.

TAJES JR., Douglas. O futebol e as realidades econômicas regionais em Santa Catarina: O futebol profissional explicado pelo desenvolvimento econômico de suas regiões. 2012. 205 f., Il. Dissertação (Mestrado) Programa de Pós-Graduação em Desenvolvimento Regional, Universidade de Contestado, 2012.

UNOSDP. Annual Report 2012.2 Disponível em: <http://www.un.org/wcm/webdav/site/sport/shared/sport/Documents /UNOSDP\%20Annual\%20Report\%202012\%20Final.pdf>. Acesso em: 17 fev. 2014.

VIDOR, Vilmar. Planejamento urbano: uma pratica não exercida em Blumenau. FURB: Revista de Divulgação Cultural, v. 9, n. 32, p. [25] 28, dez. 1986. 
Submetido em 26/02/2014

Aprovado em $02 / 12 / 2015$

\section{Sobre os autores}

\section{Marcos Antônio Mattedi}

Doutor em Ciências Sociais pela Universidade Estadual de Campinas - UNICAMP. Professor do Programa de Pós-graduação em Desenvolvimento Regional da Universidade Regional de Blumenau - FURB.

Endereço para correspondência: Max Hering, 55 apto 504 - Bairro: Victor Konder. CEP: 89012-510 - Blumenau, Santa Catarina, Brasil.

Email: mam@furb.br

\section{Camila da Cunha Nunes}

Mestre em Educação pela Universidade Regional de Blumenau - FURB e Mestre em Desenvolvimento Regional pela mesma instituição. Doutoranda no Programa de Pósgraduação em Desenvolvimento Regional da FURB. Professora do Centro Universitário de Brusque - UNIFEBE.

Endereço para correspondência: Rua Max Hering, 285 apto 505 - Bairro: Victor Konder. CEP: 89012-510 - Blumenau, Santa Catarina, Brasil.

Email: camiladacunhanunes@gmail.com 